\title{
Education: a Duty of All ${ }^{1}$
}

With 107 years, the Memórias do Instituto Oswaldo Cruz is the oldest Brazilian scientific journal. The two major funding agencies for scientific research: the National Council for Technological and Scientific Development (CNPq) and the Brazilian Federal Agency for Support and Evaluation of Graduate Education (CAPES) were only created in 1951, after the Second World War, and a major one, the São Paulo Research Foundation (FAPESP) has just turned 50.

The redemocratization of Brazil was accompanied by what has become known as the "lost decade" and only after currency stabilization could science take a big leap, reaching 13th place in the world ranking of scientific production, although Brazil still occupies the 48th position in the number of articles cited. Achieving these levels was unthinkable in the 1980s when the watchword of the scientific community was: Brazil has to have critical mass.

Today over 50 thousand Masters and $\mathrm{PhD}$ degrees are awarded annually, although this number is still low compared to the size of the Brazilian population and its national needs. To reach these numbers was only possible because there were large projects, such as, for example, the Support Program for Scientific and Technological Development (PADCT) $)^{2}$ and the research funding has not been stopped, in spite of some short periods of cuts and contingencies.

The leap taken by the Brazilian science was not, however, followed by an increase in the quality of the elementary and the high schools. Today this is the Achilles heel that undermines economic development and penalizes a large portion of the socially disadvantaged young. Basic education cannot be relegated to a second place and be considered as public spending. It should rather be seen as an investment and should appear on the priorities of the federal, state and municipal governments. Education is the main platform for the future and, for the future to be harmonious and have social welfare prevail, the government members must see education as state policy. But, this should not be restricted to the purview of the governments. Society should participate and make itself heard without exempting itself of its responsibilities.

The scientific societies have much to contribute to the improvement of the quality of the high schools, so that they can reach the same level as the developed nations and comply with quality for all school-age young people. The
Brazilian Chemical Society can, with its experience and that of its members, do its role, by embracing the cause of basic education.

It is not possible to continue living with schools that have no chemistry laboratory and where memorization pontificates in the classrooms. If this type of education is maintained, the periodic table will only be a mere table in the walls of the classrooms.

The Chemistry Institutes and Departments of the public universities should open their doors to the high school students and university professors should not ignore the schools in their districts or forget the schools in the peripheries of their cities. Some national institutes of science and technology have been showing that it is possible to take scientists to the schools and the results have been excelent. ${ }^{3}$ The $\mathrm{pH}$ of the planet was a great success. ${ }^{4}$ But, these two initiatives are outside of the curve.

The Brazilian Chemical Society must raise the flag of the basic education. It is urgent to conduct a national census to making it clear to society the true deficit of chemistry teachers in private and public systems. Also, make didactic material available in the Ministry of Education Portal for high school teachers, accompanied by education at a distance courses is another attitude that can be taken in the short term.

It is important to begin to unleash a "tsunami" for the sake of education. One swallow does not make a summer, but the Brazilian Chemical Society and its members can revolutionize chemistry in the high schools and change Brazil for the better. In this country everything is very recent, including democracy. Without education there is no future and democracy is only window-dressing.

Angelo C. Pinto JBCS Editor

\section{References}

1. Pinto, A. C.; J. Braz. Chem. Soc. 2012, 23, 985.

2. De Castro, L. A. B.; Prescott, E.; Quim. Nova 1997, 20 special number, 15.

3. Guarieiro, L. L. N.; Costa, E. A. A.; Victor, M. M.; Riatto, V. B.; Lopes, W. A.; Leite, O. D.; Braga, V. S.; Lucena, P. R.; Mangrich, A. S.; Rev. Virtual Quim. 2011, 3, 361.

4. Pinto, A. C.; Galembeck, F.; de Andrade, J. B.; J. Braz. Chem. Soc. 2012, 23, 373. 